O impressionante é o corpo. Isso quer dizer o que? É uma reação de certos filósofos que dizem: escutem, parem com a alma, com a consciência, etc. Vocês deveriam antes tentar ver um pouco, de início, o que pode o corpo. O que é...? Não sabem nem mesmo o que é um corpo e vêm falar da alma. Então não, é preciso ultrapassar

Deleuze, Curso sobre Spinoza.

\title{
o que pode um corpo?
}

Nosso trabalho nasce dessa provocação. Deste questionamento e das reflexões que nosso próprio corpo pode manifestar sem o recurso sedutor da linguagem no uso da razão. Queremos esse retorno ao corpo, queremos repensar através do desejo a nossa relação com o nosso corpo e o corpo do outro. Partindo de uma questão indiretamente levantada por Espinosa, e que na verdade pode nos evocar uma dupla questão. Queremos pensar a estrutura de um corpo, e dada esta estrutura, o que está em seu poder. Se o nosso corpo não é passivo, se ele não é um instrumento da alma nem mero objeto negligenciável, então cabe a nós refletir sobre qual é o seu lugar e como nós podemos entendê-lo.

\section{Janela sobre o corpo}

Igreja diz: O corpo é uma culpa.

A ciência diz: O corpo é uma máquina.

O corpo diz: Eu diz: O corpo é um negócio.

Eduardo Galeano 


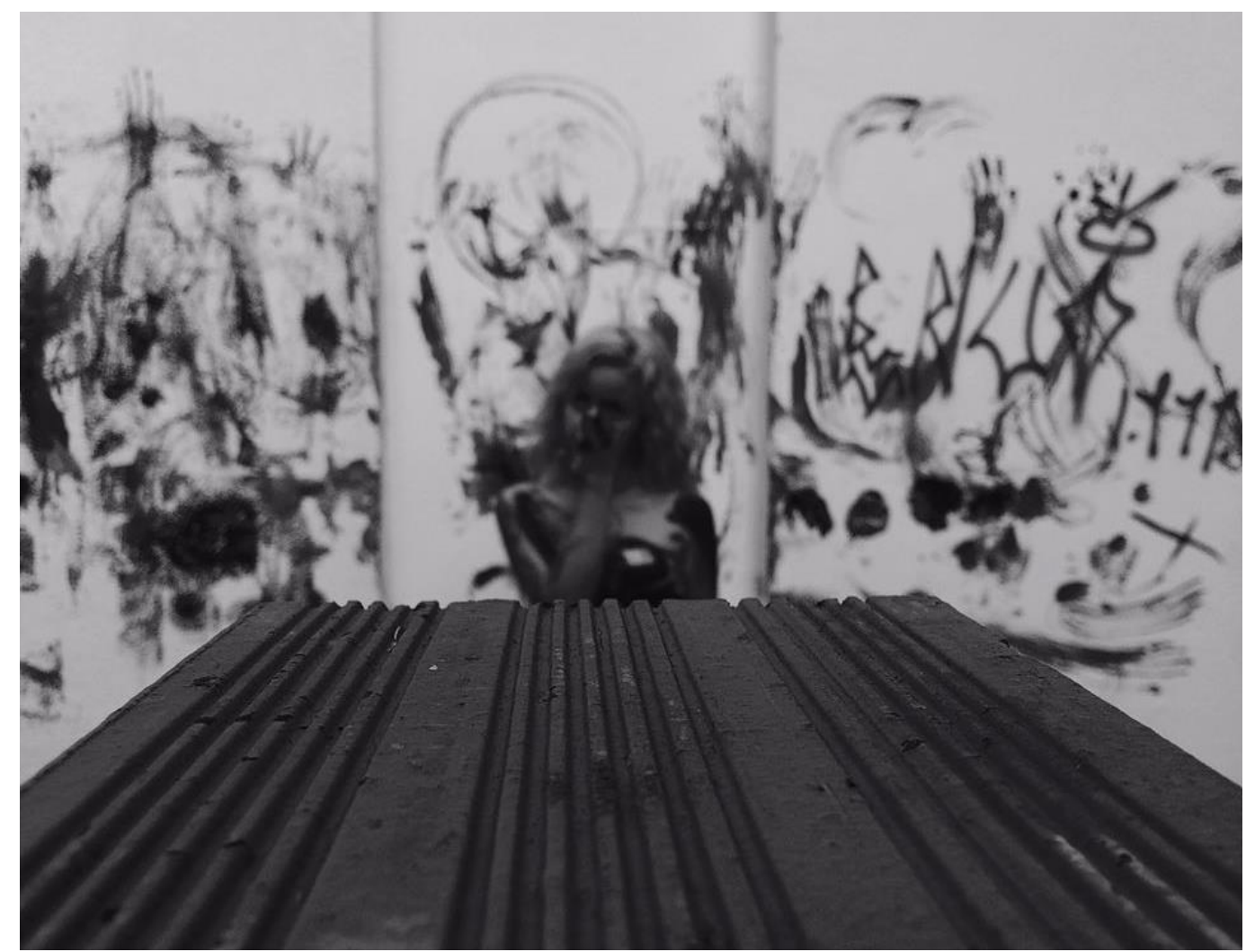

O fato é que ninguém determinou, até agora, o que pode o corpo, isto é, a experiência a ninguém ensinou, até agora, o que o corpo - exclusivamente pelas leis da natureza enquanto considerada apenas corporalmente, sem que seja determinado pela mente - pode e o que não pode fazer

Espinosa - Ética III, Proposição 2 

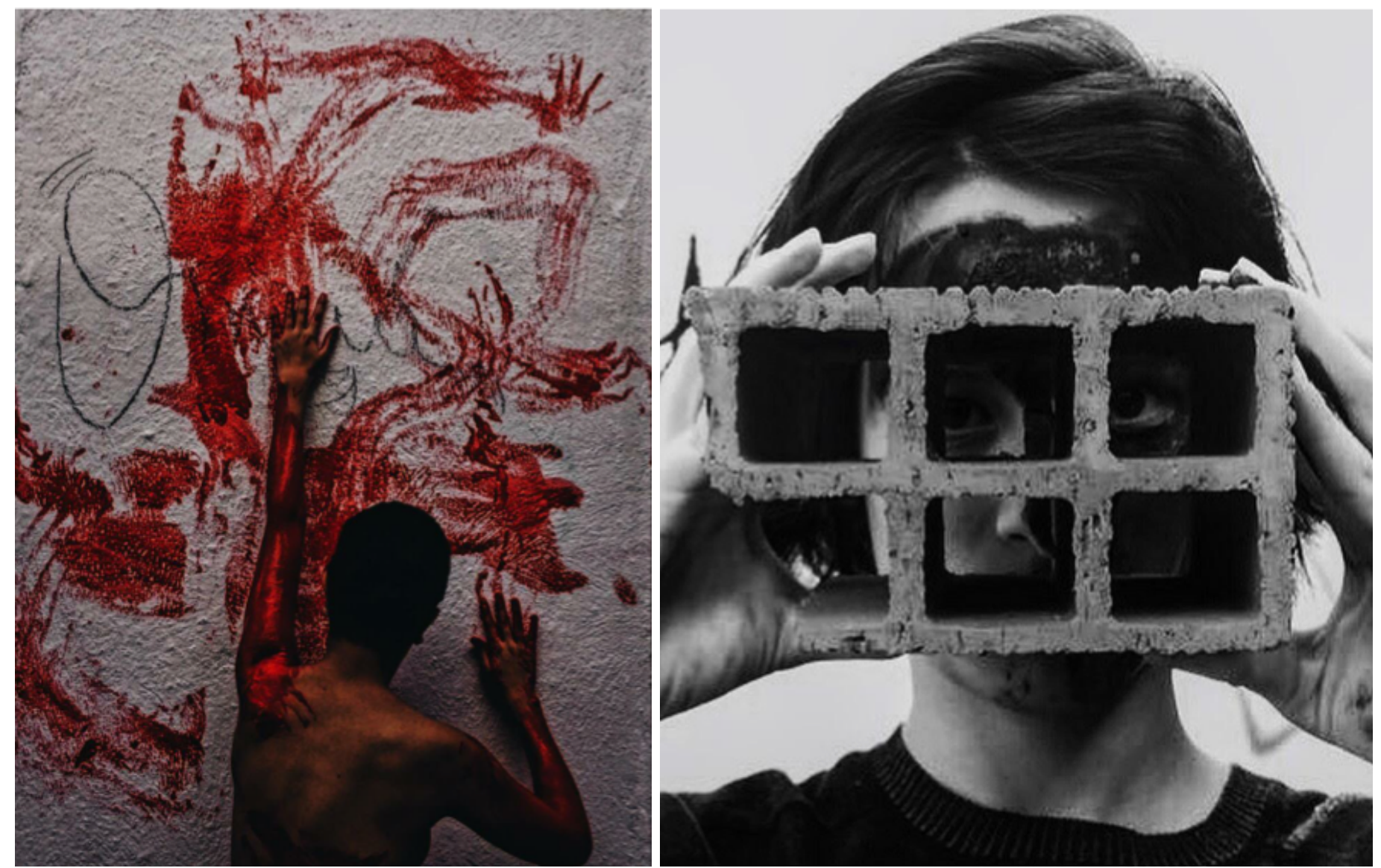

Nosso corpo é essa dança com movimento ritmado. Que mesmo estando parado, dança.

As veias pulsam, o coração tem ritmo, os olhos piscam e a melodia dos órgãos pode não ser ouvida por estarmos passando a vida toda submersos na sua sinfonia. 
METAgraphias: letra D de dropbox (das derivas dançantes) v.2 n.1 marçol2017 o que pode um corpo? • Coletivo Campo Minado Carolina Antunes; Diana Ricarte; Giovana Melo; Maria Luiza Porto; Monike Cardoso; Raiany Carvalho; Vanessa Liberato

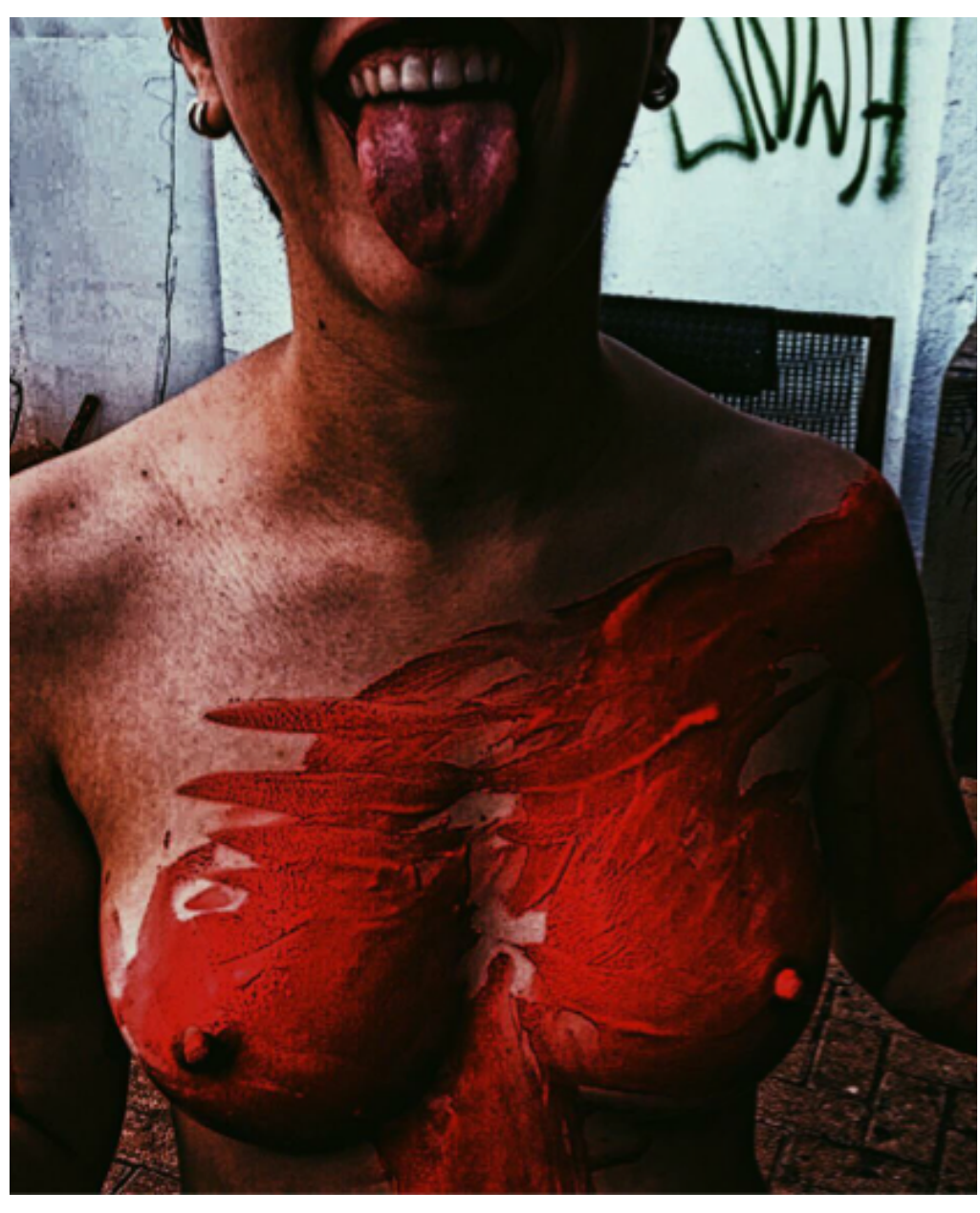

Não seria esse o problema? $\bigcirc$ status quo que nos ensurdece? Não seria a hora de nos procurarmos? Somos este corpo. Que se esforça para se tornar mais forte, mais disposto a se regenerar através de sua capacidade de transformação e de seu relacionamento plural com o mundo fora dele. A pele como o limite que separa o ser do mundo que o cerca. Quanto mais plural nosso modo de agir, quanto mais complexos os nossos movimentos, maiores nossas afetações diante do mundo. Por sermos tão complexos, nosso corpo se torna capaz de muitas coisas, por sermos feitos de várias partes ele é capaz de ser afetado de muitas formas e agir de tantas outras. Um leque de possibilidades. Entretanto, atualmente ele está separado de sua capacidade de ser afetado, seus poros estão entupidos, colonizados pelos valores de uma sociedade corrompida 
O que pode então o nosso corpo? Que sensações e percepções ele pode experimentar, captar? Onde estamos enquanto nosso corpo sempre está? Ele que sempre se movimenta mesmo estando imóvel? Experimentamos o suficiente? Nossos corpos estão dóceis para experimentar, é preciso desafiar o corpo. Transgredir a sua função utilitária. Experimentar no sentido de se apropriar do presente, reaprender a não nos omitir do que nos ocorre, não fazer vista grossa. Fazer da experiência, não uma soma quantitativa de consumo, mas uma apreensão qualitativa. Apropriando-nos do mundo enquanto nos (re)apropria-mos de nós mesmas. Muitas de nós morrem sem jamais saber do que são capazes, sem jamais se surpreender com seu próprio corpo. A saída é a tomada de poder, o reinvestimento em nós mesmas e a união de nossas forças para desestruturação da normalidade

pré-estabelecida. 
METAgraphias: letra D de dropbox (das derivas dançantes) v.2 n.1 marçol2017

o que pode um corpo? • Coletivo Campo Minado

Carolina Antunes; Diana Ricarte; Giovana Melo; Maria Luiza Porto; Monike Cardoso; Raiany Carvalho; Vanessa Liberato

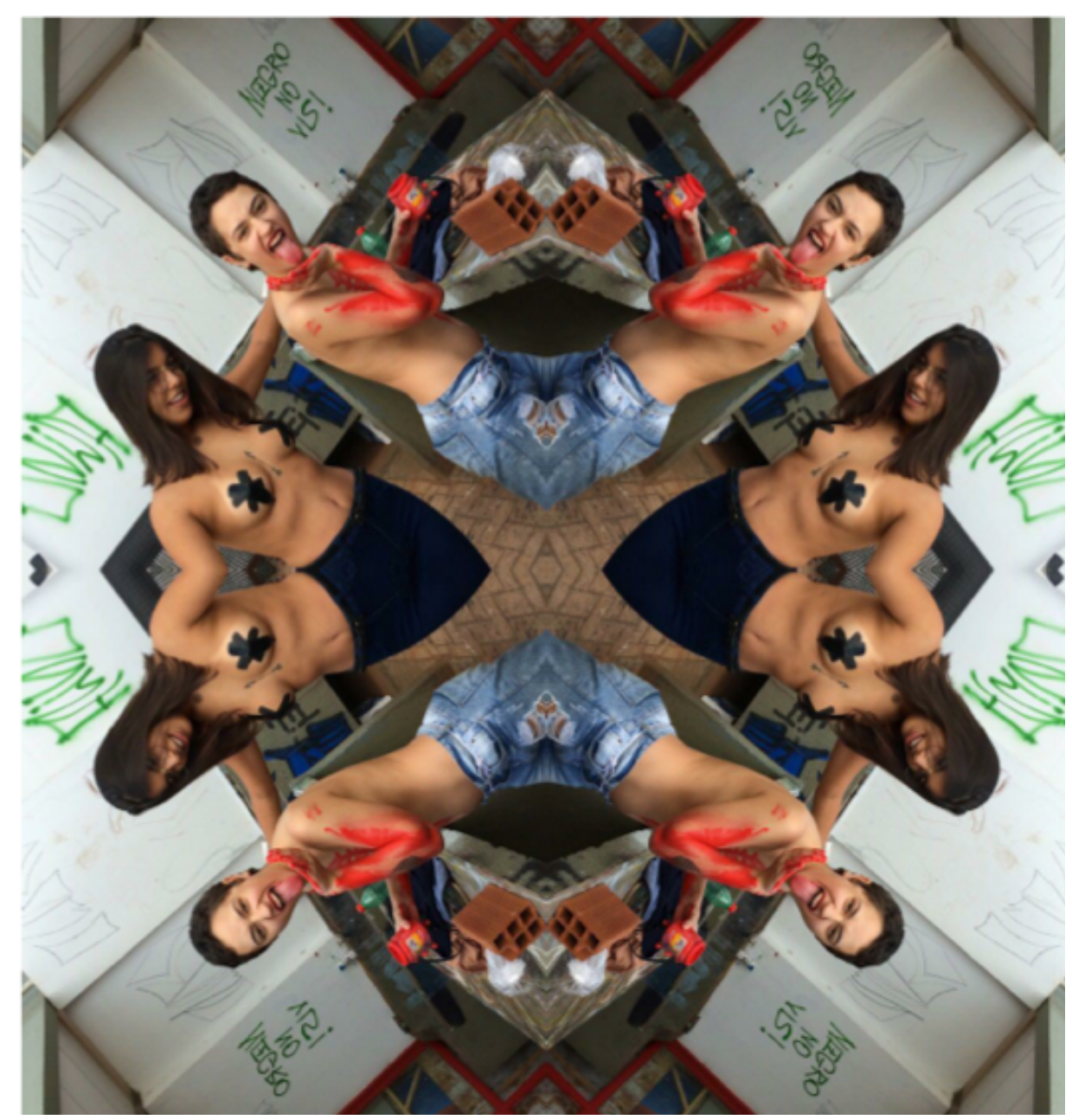




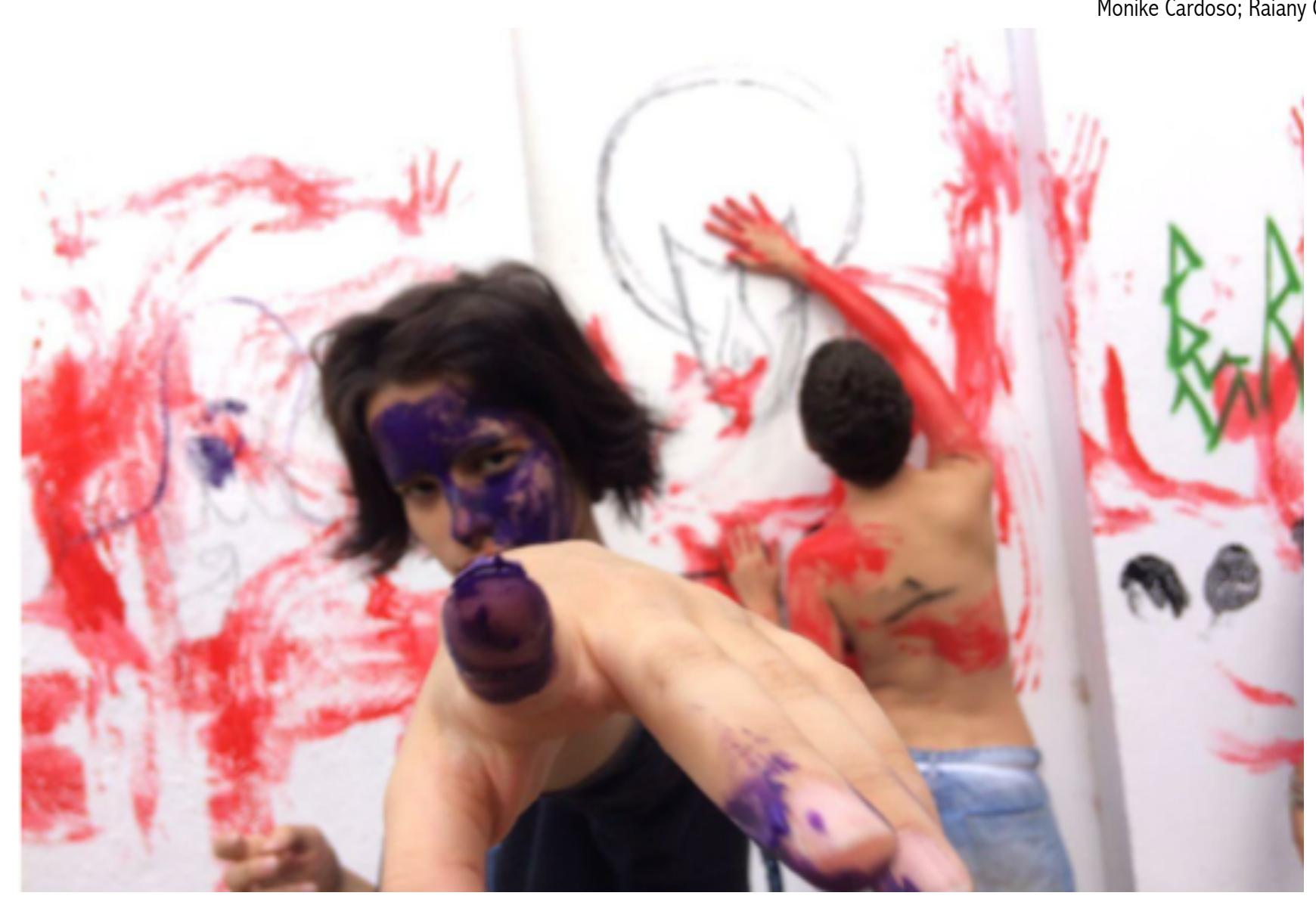

Valorizar o corpo significa valorizar a vida que trazemos em nós,

Não somos suportes para outras coisas, nosso corpo é tudo que temos.

Ele vale tudo que pode e é definido em sua própria potência. Efetuamos nossas possibilidades ao máximo.

A estrutura de um corpo é a composição da sua relação.

O que pode um corpo é a natureza e os limites do seu poder de ser afetado. 
E como podemos nos potencializar? Espinoza dirá que é na experimentação, nas relações que estabelecemos com o mundo. A potência definirá nosso corpo e este será constantemente afetado. E estes afetos aumentarão ou diminuirão a nossa perfeição, a nossa capacidade inventiva e evolutiva. Chamará o afetar e ser afetado de bons ou maus encontros, nos modificando e aumentando nossa capacidade de sermos novamente afetados por outros corpos, por outros mundos e modos.

Aquele que tem um corpo capaz de muitas coisas, tem uma mente que, considerada em si mesma, possui uma grande consciência de si, de Deus e das coisas. Assim, esforçamo-nos, nesta vida, sobretudo, para que o corpo de nossa infância se transforme, tanto quanto o permite a sua natureza e tanto quanto lhe seja conveniente, em um outro corpo, que seja capaz de muitas coisas e que esteja referido a uma mente que tenha extrema consciência de si mesma, de Deus e das coisas" - Espinosa, Ética V, Prop. 39, esc.

Criar um corpo que experimenta e que pode ir cada vez mais além, um corpo que escolhe tudo o que lhe convém sempre da melhor maneira possível, um corpo feliz, satisfeito, realizado. Deixar definitivamente esta corporeidade moral, que julga, cultua, idealiza, esquece de si, se despreza, tem nojo, medo, vergonha e abrir todo um novo plano de sensações novas dentro de nós, um novo topos, uma nova região. O corpo visto como geografia, não como história. O corpo que experimenta, não que interpreta. Isso torna as possibilidades infinitas, cada nova experiência abre uma porta inédita, nunca antes explorada. $\mathrm{Na}$ relação, quando nos modificamos automaticamente, nossa essência se atualiza. Viver é estar em relação e criar organizações corporais totalmente novas, inéditas, impensadas, há pouco impossíveis, e muito melhores que estas que nos ofereceram. 
METAgraphias: letra D de dropbox (das derivas dançantes) v.2 n.1 marçol2017

o que pode um corpo? • Coletivo Campo Minado

Carolina Antunes; Diana Ricarte; Giovana Melo; Maria Luiza Porto; Monike Cardoso; Raiany Carvalho; Vanessa Liberato

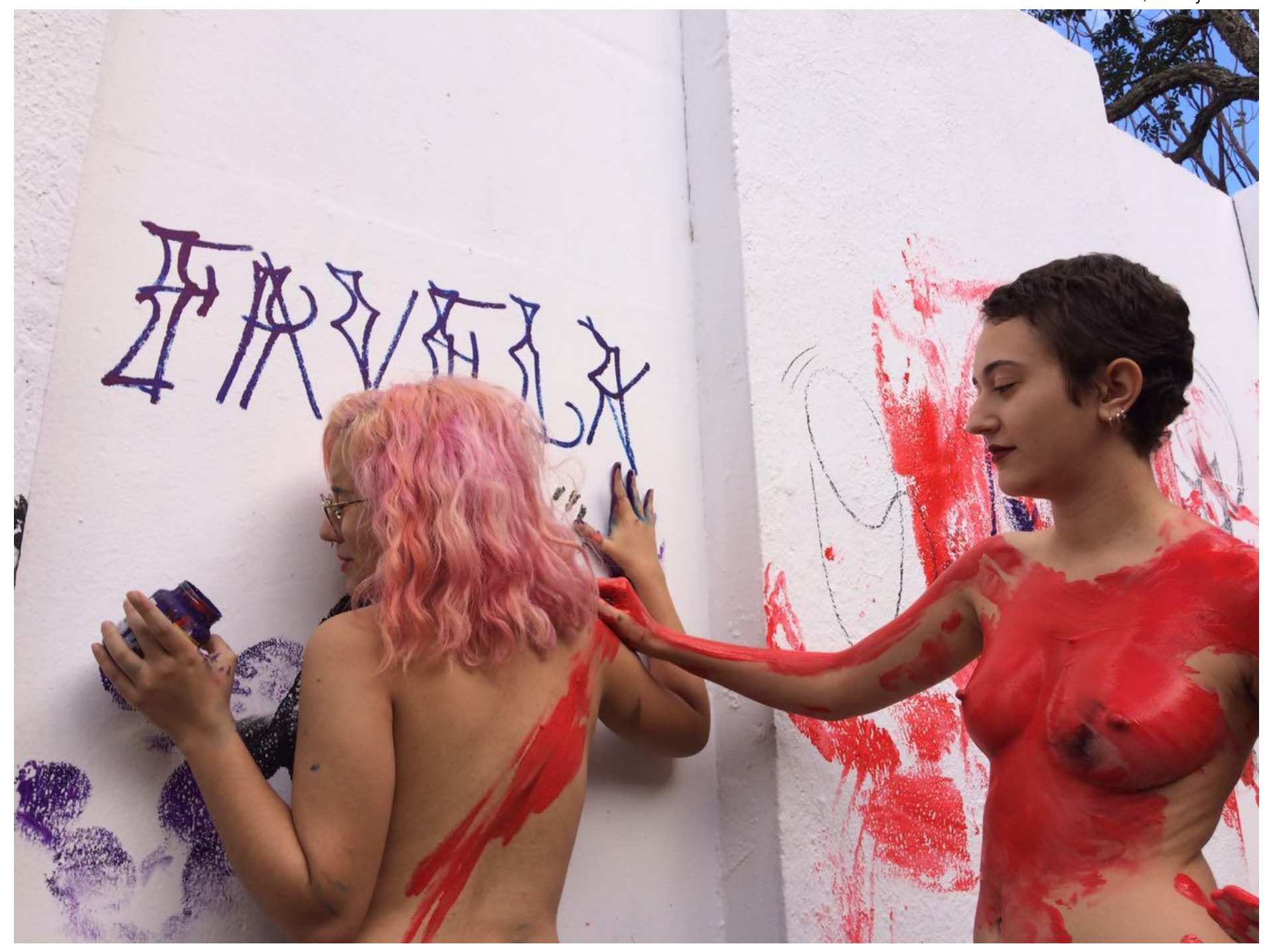


METAgraphias: letra D de dropbox (das derivas dançantes) v. 2 n.1 março|2017

o que pode um corpo? • Coletivo Campo Minado

Carolina Antunes; Diana Ricarte; Giovana Melo; Maria Luiza Porto; Monike Cardoso; Raiany Carvalho; Vanessa Liberato

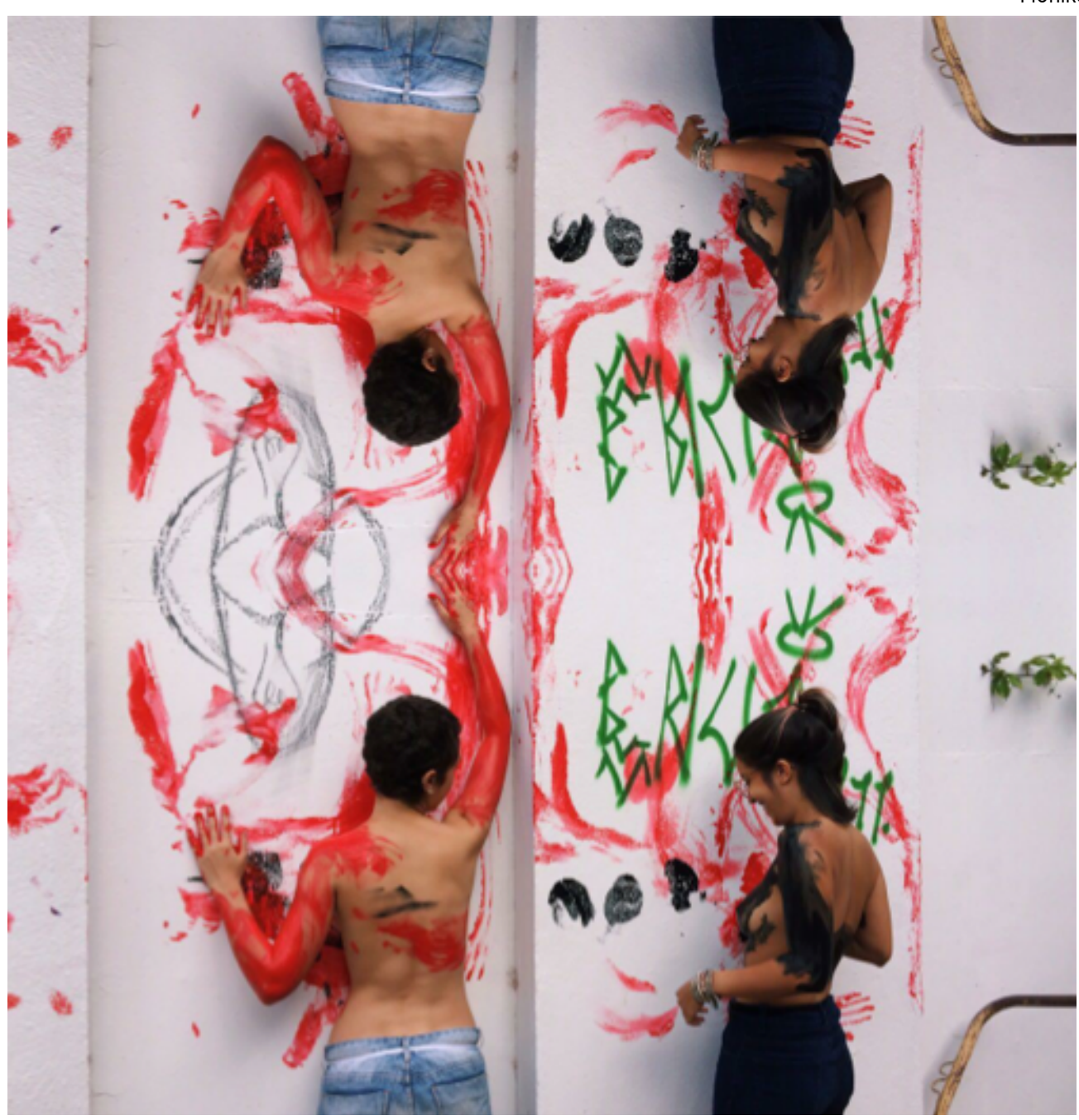

